\title{
LIFE CYCLE COST ANALYSIS OF BBTM AND TRADITIONAL ASPHALT CONCRETES IN LATVIA
}

\author{
Arturs Riekstins ${ }^{1,2}$, Viktors Haritonovs ${ }^{1}$, Valters Abolins ${ }^{1,3}$, Verners Straupe ${ }^{1,4}$, Janis Tihonovs ${ }^{1,2}$ \\ ${ }^{1}$ Riga Technical University, Latvia; ${ }^{2}$ SJSC Latvian State Roads, Latvia; ${ }^{3}$ Institute of Electronics and \\ Computer Science, Latvia; ${ }^{4} \mathrm{SC}$ "Celuprojekts", Latvia \\ riekstins.arturs@gmail.com, viktors.haritonovs@rtu.lv, valters.abolins@edi.lv, \\ verners@celuprojekts.lv, janis.tihonovs@gmail.com
}

\begin{abstract}
Effective investing of public money in the road infrastructure should be the basis for construction of new roads or reconstruction of the existing ones. Funding for the maintenance of the road infrastructure in Latvia has been insufficient since the restoration of independence. This means the existing budget funds should be used sustainably. One of the solutions that are offered is the use of thin asphalt layers (BBTM). This solution has proven to be a cost-effective and sustainable asphalt wearing course. One of the main problems at the road design stage is to determine which asphalt concrete types would be most beneficial in the long-term due to the maintenance cost, which can significantly increase the overall cost. The current practice in Latvia is that there are some guidelines for choosing the best asphalt concrete types depending on the intensity. However, the initial construction costs do not reflect the costs of the owner to restoring and maintaining this road in the long term; for example, for a period of 40 years. For this purpose, the life cycle cost analyses (LCCA) is widely used worldwide. It is a method based on statistical data and the probable distribution of their forecasts, which makes it possible to compare different options for the road pavement. The aim of this study is to evaluate the possibilities of using thin asphalt concrete layers (BBTM) in Latvia and to compare it with traditionally used asphalt layers using the life-cycle cost analysis (LCCA). High-performance results were obtained from the Wheel Tracking test and Shear test during the research of testing a thin asphalt layer (BBTM) in the laboratory. Also, the life cycle cost analysis (LCCA) of asphalt mixes was performed for the road section.
\end{abstract}

Keywords: LCCA, BBTM, sustainability, maintenance, reconstruction.

\section{Introduction}

Due to limited funding in Latvia and around the world, new ways are being examined to make the renovation of the existing road surfaces as cheap and efficient as possible. According to the latest estimates, the Latvian State Road repair deficit is over 4 billion euros. [1] Each year, traffic on roads continues to increase [2]. Lack of money forces existing funds to be used as efficiently as possible. For a long time, in choosing the road pavement design, the main criterion has been the initial construction cost. However, this approach does not reveal how long the construction will last, nor its costs in the long term. The service life of the built structure and reconstructed layers has a major impact on LCCA results. [3] Cheap and poor-quality asphalt layers could have a short service life and high maintenance costs. Furthermore, asphalt concrete is the most expensive component in road pavement. That is why it is important to evaluate which pavement type would be the most beneficial in the long term.

Life Cycle Cost Analysis (LCCA) is an evaluation method that uses economic analysis to estimate costs over the entire calculation period [3]. The basic precondition for the accuracy of this method is the amount of data entered, their reliability and possible dispersion. For the construction of the road, the LCCA analysis is mainly carried out for a 40-year period, which is a realistic lifetime for road pavement that has been preventively maintained. In this study, the LCCA analysis was performed only on the cost side of the building owner. There are two calculation approaches which are mainly used for LCCA:

- The Deterministic Approach to LCCA applies procedures and techniques without regard for the variability of the inputs. The primary disadvantage of this traditional approach is that it does not account for the variability associated with the LCCA input parameters. [3];

- The Risk Analysis Approach, in which output data cannot be predicted reliably (common factors include: increase in traffic, the number of heavy trucks, building material prices, duration of construction work, etc.), is described with the theoretical probability chosen by the authors of this study. In this way, the mathematical algorithm of the analysis becomes more complicated and approximated calculation methods are applied (e.g., Monte-Carlo simulations or other iterative methods). The results obtained are no longer as accurate, but rather are interpreted as a new distribution of probability, which is predominantly specific and 
individual to each example; the most significant value of the life cycle analysis parameter is obtained as well as its expected dispersion.

In this LCCA, the results were obtained by calculating both with the Deterministic approach and by the Risk Analysis approach. To perform LCCA analysis, it is necessary to offer different alternatives to the basic option. Therefore, different types of asphalt concrete that are not used in Latvia have been studied. Thin layer asphalt concrete (BBTM), which allows reducing the thickness of the wearing course, has gained wide popularity in the world [4]. BBTM compositions were developed according to EN 13108-2 [5]. It was found that BBTM has high rutting resistance and interlayer shear strength. However, further LCCA analysis would be needed to support the use of this overlay as a sustainable alternative.

\section{Development of LCCA Analysis Model}

\section{LCCA stages}

LCCA for building includes several life stages:

1. planning and designing of the construction;

2. manufacture of raw materials and equipment;

3. construction (demolition and removal of old construction; logistics of new building materials to and from the site);

4. maintenance of the construction during operation, reconstruction and repair work;

5. demolition or full reconstruction of the construction site [6];

In this study, stages B, C, and D were evaluated. The planning and designing of the construction were assumed to be the same for all options and were not individually assessed. Similarly, the stage of demolition or full reconstruction was not assessed. It was assumed that the residual construction value was not taken into the LCCA calculation.

Various LCCA and LCA freely available programs were considered. However, they had various drawbacks. Therefore, it was decided to create our own program, which could be freely modified. The calculation was based on MS Excel. The parameters included in Life Cycle Cost Analysis:

1. Volume of materials for construction, reconstruction, milling;

2. Properties of materials used;

3. Price of materials;

4. Provisional service life;

5. Road pavement construction options;

6. Parameters of construction machinery used for construction, reconstruction, milling;

7. Preliminary maintenance costs;

8. Discount rate.

\section{Assumptions}

Various assumptions were made to simplify the calculation:

- In the road construction LCCA the period should be long enough to include the impact of its service life. For this reason, 40 years were chosen as the analysis period;

- Since the aim was to compare the cost differences between different types of asphalt concrete, no previous activities (raw material production, pavement construction, road equipment) were taken into account;

- LCCA compares the base option with alternative options;

- Purchase and maintenance of construction machinery or other equipment at any stage of the life cycle is not considered;

- The residual road value is not calculated at the end of the life cycle;

- Calculation is made for 40 years (it did not matter whether the renewal of the wearing course or base course was carried out in the 39th year);

- The cost of moving construction machinery and labour to and from the site was not taken into account;

- There was no need to repair large potholes during the life cycle, because the road was preventively maintained; 
- $100 \%$ new material was used to produce the surface and base course;

- Weather conditions had no effect on construction performance;

- By adjusting the calculation for the Latvian climate, we assumed that the reconstruction work was only carried out in summer.

- Thickness of the pavement structures was taken from experience.

Road section

The main criterion for choosing a road section was that it had been already built to simplify data collection. The national regional road P5 Ulbroka - Ogre was selected. For the reconstructed section, the AC 11 wearing course and the AC 22 type base course were built. The average daily traffic intensity of the road P5 Ulbroka - Ogre from 20.54 to 25.00 kilometres in 2014 was $3692 \mathrm{a} / 24 \mathrm{~h}$, of which the percentage of heavy trucks was $3 \%$.

\section{Road pavement options}

To be able to compare the economic benefits of this base option, alternatives to the wearing and base course were needed to be included in the calculation. For the wearing course, an alternative SMA and BBTM were investigated. For the base course, an alternative HMAC was investigated. Five different alternatives were created for the constructed and existing road pavement. Table 1 below shows six different options for road pavement.

6 various road pavement construction options for P5 road

Table 1

\begin{tabular}{|c|c|c|c|c|c|c|c|c|c|c|c|}
\hline $\begin{array}{c}\text { Base } \\
\text { A }\end{array}$ & $\mathbf{h}, \mathbf{c m}$ & $\begin{array}{c}\text { Option } \\
\text { B }\end{array}$ & $\begin{array}{l}\text { h, } \\
\text { cm }\end{array}$ & $\begin{array}{c}\text { Optio } \\
\text { n C }\end{array}$ & h, cm & $\begin{array}{c}\text { Option } \\
\text { D } \\
\end{array}$ & $\begin{array}{l}\text { h, } \\
\text { cm }\end{array}$ & $\begin{array}{c}\text { Option } \\
\text { E }\end{array}$ & $\begin{array}{l}\text { h, } \\
\text { cm }\end{array}$ & $\begin{array}{c}\text { Option } \\
\text { F }\end{array}$ & $\begin{array}{l}\text { h, } \\
\text { cm }\end{array}$ \\
\hline $\begin{array}{c}\mathrm{AC} 11 \\
\text { surf }\end{array}$ & 4 & $\begin{array}{c}\text { SMA11 } \\
\text { surf }\end{array}$ & 3.5 & $\begin{array}{l}\text { BBTM } \\
11 \text { surf }\end{array}$ & 2.5 & $\begin{array}{c}\mathrm{AC} 11 \\
\text { surf }\end{array}$ & 4 & $\begin{array}{c}\text { SMA11 } \\
\text { surf }\end{array}$ & 3.5 & $\begin{array}{l}\text { BBTM } \\
11 \text { surf }\end{array}$ & 2.5 \\
\hline $\begin{array}{c}\mathrm{AC} 22 \\
\text { bin }\end{array}$ & 6 & $\begin{array}{c}\mathrm{AC} 22 \\
\text { bin }\end{array}$ & 6 & $\begin{array}{c}\mathrm{AC} 22 \\
\text { bin }\end{array}$ & 6 & $\begin{array}{c}\text { HMAC } \\
16 \text { bin }\end{array}$ & 5 & $\begin{array}{c}\text { HMAC } \\
16 \text { bin }\end{array}$ & 5 & $\begin{array}{l}\text { HMAC } \\
16 \text { bin }\end{array}$ & 6 \\
\hline \multicolumn{12}{|c|}{ Crushed mixture (basic top layer 0/45) $-16 \mathrm{~cm}$} \\
\hline \multicolumn{12}{|c|}{ Crushed mixture (basic sublayer 0/56) $-20 \mathrm{~cm}$} \\
\hline \multicolumn{12}{|c|}{ Medium coarse sand $-55 \mathrm{~cm}$} \\
\hline & & & & & Natur & 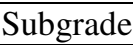 & & & & & \\
\hline
\end{tabular}

Reconstruction plan

For the above-described combinations a calendar of construction, maintenance, and reconstruction was created.

- Environment;

- Drainage;

- Construction;

- Material quality [7].

Literature analysis was conducted on how long different types of wearing course mixtures could endure. Values were obtained in a very wide range (see Table 2). The service life for a base course depended directly on how well the wearing course was maintained. Therefore, if the surface has been preventively maintained, then it can serve for more than 20 years.

Table 2

Service life of different wearing courses

\begin{tabular}{|c|c|c|c|c|c|c|c|c|c|c|}
\hline $\begin{array}{c}\text { Wearing } \\
\text { course }\end{array}$ & \multicolumn{3}{|c|}{$\begin{array}{c}\text { AC11 (Asphalt } \\
\text { Concrete) }\end{array}$} & \multicolumn{3}{c|}{$\begin{array}{c}\text { SMA11 (Stone } \\
\text { Mastic Asphalt) }\end{array}$} & \multicolumn{4}{c|}{$\begin{array}{c}\text { BBTM11 (Béton } \\
\text { Bitumineux Très Mince) }\end{array}$} \\
\hline Service life & $7-18$ & 6 & 8 & $10-16$ & $14-25$ & 10 & $11-15$ & $8-18$ & 7 & 6 \\
\hline References & {$[8]$} & {$[9]$} & {$[10]$} & {$[11]$} & {$[8]$} & {$[12]$} & {$[11]$} & {$[8]$} & {$[13]$} & {$[14]$} \\
\hline
\end{tabular}

Due to the high scattering of the results, it was assumed that the average service life would be selected by consulting with SJSC "Latvian State roads" main road construction engineers, who had real experience and opinions about the current situation of the service life for asphalt concrete types. 
In the follow-up study, it was planned to test different asphalt mixes on physical tests, as it had been done in the Durab Roads research [15]. It was planned to perform experiments using several tests - Fatigue test, Dynamic Module, Wheel Track test, and on Interlayer Shear. After that, the general idea was to compare these materials and ultimately predict their service life.

The lifetime of road pavement was planned to last for 40 years. During these years, the maintenance of the road wear cycle, its replacement and replacement of all asphalt layers were carried out. Table 3 shows the road pavement construction, maintenance and reconstruction plan. There are alternatives for a plan, which can be seen in Table 3. For example, it is possible to lay a thin layer on an existing surface (BBTM, chip seal, slurry seal, microsurfacing). This would save money on milling, while increasing the bearing capacity of the pavement. However, in this study, this factor was not considered. The life cycle plan of road pavement will be specified by developing the LCCA analysis.

Road Pavement Life Cycle Plan (LCCA Deterministic Approach)

Table 3

\begin{tabular}{|c|c|c|c|c|c|c|c|c|c|c|c|}
\hline \multicolumn{2}{|c|}{ A } & \multicolumn{2}{c|}{ B } & \multicolumn{2}{c|}{ C } & \multicolumn{2}{c|}{ D } & \multicolumn{2}{c|}{ E } & \multicolumn{2}{c|}{ F } \\
\hline $\begin{array}{c}\text { AC11 + } \\
\text { AC22 }\end{array}$ & \multicolumn{2}{c|}{$\begin{array}{c}\text { SMA11 + } \\
\text { AC22 }\end{array}$} & \multicolumn{2}{c|}{$\begin{array}{c}\text { BBTM11 + } \\
\text { AC22 }\end{array}$} & \multicolumn{2}{c|}{$\begin{array}{c}\text { AC11 + } \\
\text { HMAC16 }\end{array}$} & \multicolumn{2}{c|}{$\begin{array}{c}\text { SMA11 + } \\
\text { HMAC16 }\end{array}$} & \multicolumn{2}{c|}{$\begin{array}{c}\text { BBTM11 + } \\
\text { HMAC16 }\end{array}$} \\
\hline IC & 0 & IC & 0 & IC & 0 & IC & 0 & IC & 0 & IC & 0 \\
\hline W & $0-5$ & W & $0-5$ & W & $0-5$ & W & $0-5$ & W & $0-5$ & W & $0-5$ \\
\hline M & $5-10$ & M & $5-12$ & M & 8 & M & $5-11$ & M & $5-13$ & M & $5-12$ \\
\hline ROWC & 10 & ROWC & 12 & ROWC & 11 & ROWC & 11 & ROWC & 13 & ROWC & 12 \\
\hline W & $10-13$ & W & $12-15$ & W & $11-14$ & W & $11-14$ & W & $13-16$ & W & $12-15$ \\
\hline M & $13-20$ & M & $15-24$ & M & $14-22$ & M & $14-22$ & M & $16-26$ & M & $15-24$ \\
\hline ROBM & 20 & ROBM & 24 & ROBM & 22 & ROBM & 22 & ROBM & 26 & ROBM & 24 \\
\hline W & $20-23$ & W & $24-27$ & W & $22-25$ & W & $22-25$ & W & $26-29$ & W & $24-27$ \\
\hline M & $23-30$ & M & $27-36$ & M & $25-33$ & M & $25-33$ & M & $29-39$ & M & $27-36$ \\
\hline ROWC & 30 & ROWC & 36 & ROWC & 33 & ROWC & 33 & ROWC & 39 & ROWC & 36 \\
\hline W & $30-33$ & W & $36-39$ & W & $33-36$ & W & $33-36$ & W & $39-40$ & W & $36-39$ \\
\hline M & $33-40$ & M & $39-40$ & M & $36-40$ & M & $36-40$ & & & M & $39-40$ \\
\hline \multicolumn{7}{|c|}{} \\
\hline
\end{tabular}

Notes: IC - Initial construction;

W - Warranty period;

M - Maintenance period;

ROWC - Replacement of the wearing course;

ROBM - Replacement of bituminous mixtures.

\section{Monte Carlo Simulation (LCCA Probabilistic Approach)}

Since the period when the wearing course is going to be replaced may change (not always as predicted, for example, ten years), we performed the Monte Carlo Simulations to predict potential costs, if there is any deviation from the planned reconstruction calendar. Assuming that for the first option an average service life for a road wearing course is 10-years, during this time 20,000 values were generated, following a normal distribution with an average value of 10 years and a standard deviation of 2 years. With this method, we can calculate the probability that the costs will not exceed a certain amount or how high is the probability that they will be within certain limits.

This kind of simulations were performed for all six road pavement construction options. With an average lifetime of 10 years for the base option A, 12 years for option B, 11 years for option $\mathrm{C}, 11$ for option D, 13 for option E, and 12 years for option F. Standard deviations for all options were two years.

All data were processed and calculated using a custom written script in Python[16]. Since 20,000 iterations generated a reliable normal distribution, and the program execution time would not be too long, the number of the generated values was limited to 20,000. The script is flexible, and its generated value distribution and number can be easily changed. By significantly reducing the number of the generated values, the program speeds up. Although, doing so will also decrease the accuracy of the generated distribution, and the results will be less accurate. 


\section{Results}

Results of LCCA The Deterministic Approach

In the Deterministic Approach, each pavement option obtained its own cost results. The results of the calculation were general as no calculations of bearing capacity were carried out, which can significantly change the thickness of the layers in the pavement construction. The results are shown in Figure 1 for all options. The calculation was based on the impact of various assumptions which will decrease as the research develops. According to the results obtained, the most sustainable construction option is $\mathrm{C}$, which is the wearing course BBTM11 and the base course AC22.

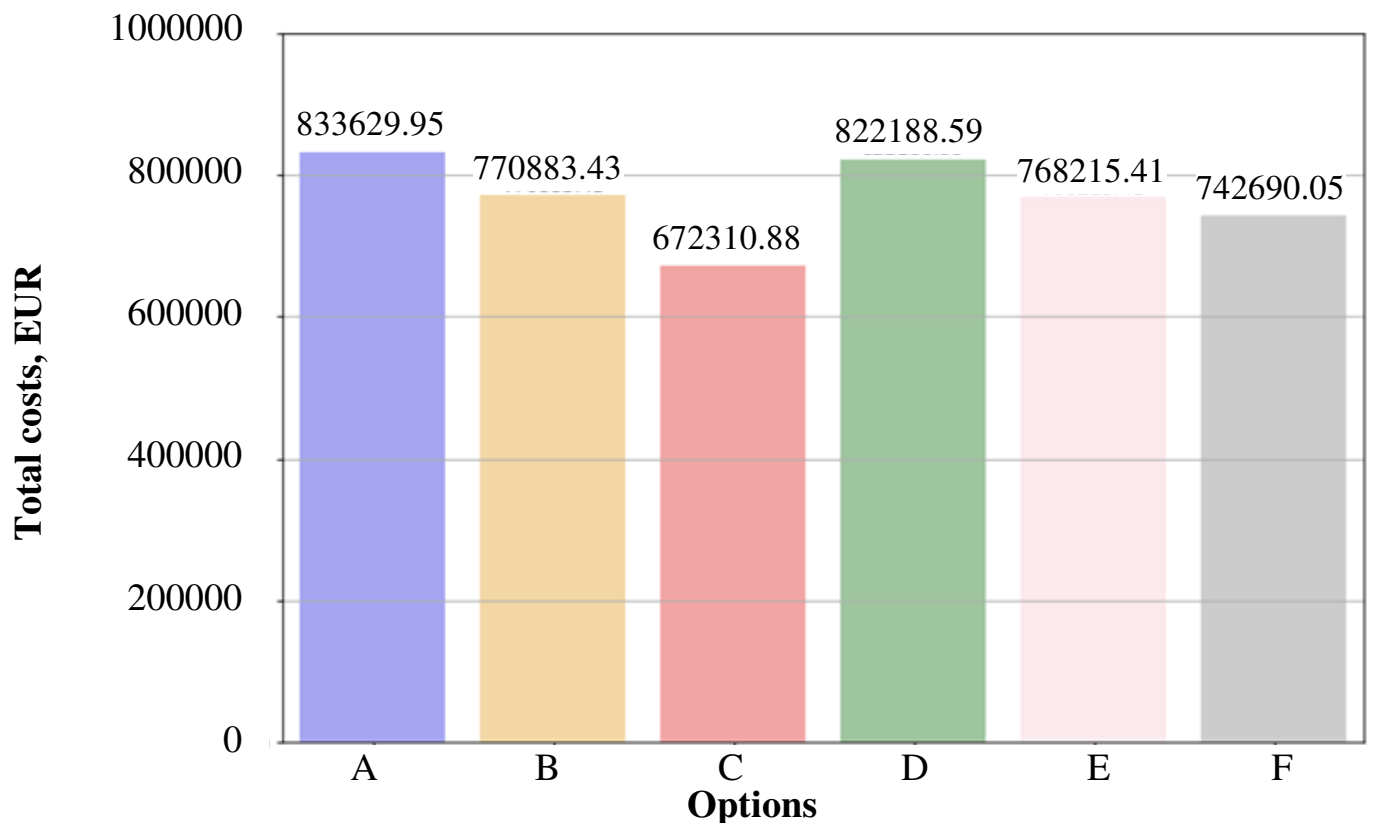

Fig. 1. Results of LCCA Deterministic Approach

Results of LCCA Probabilistic Approach.

The median of option A (EUR 833629.95) has the highest value in relation to the other options (see Figure 2). The coefficient in fluctuation of option A (17.6\%) is also higher than for the other options, which range from $10.1 \%$ to $14.9 \%$. The highest deviation from the estimated value is for options A and D, (see Figure 3).

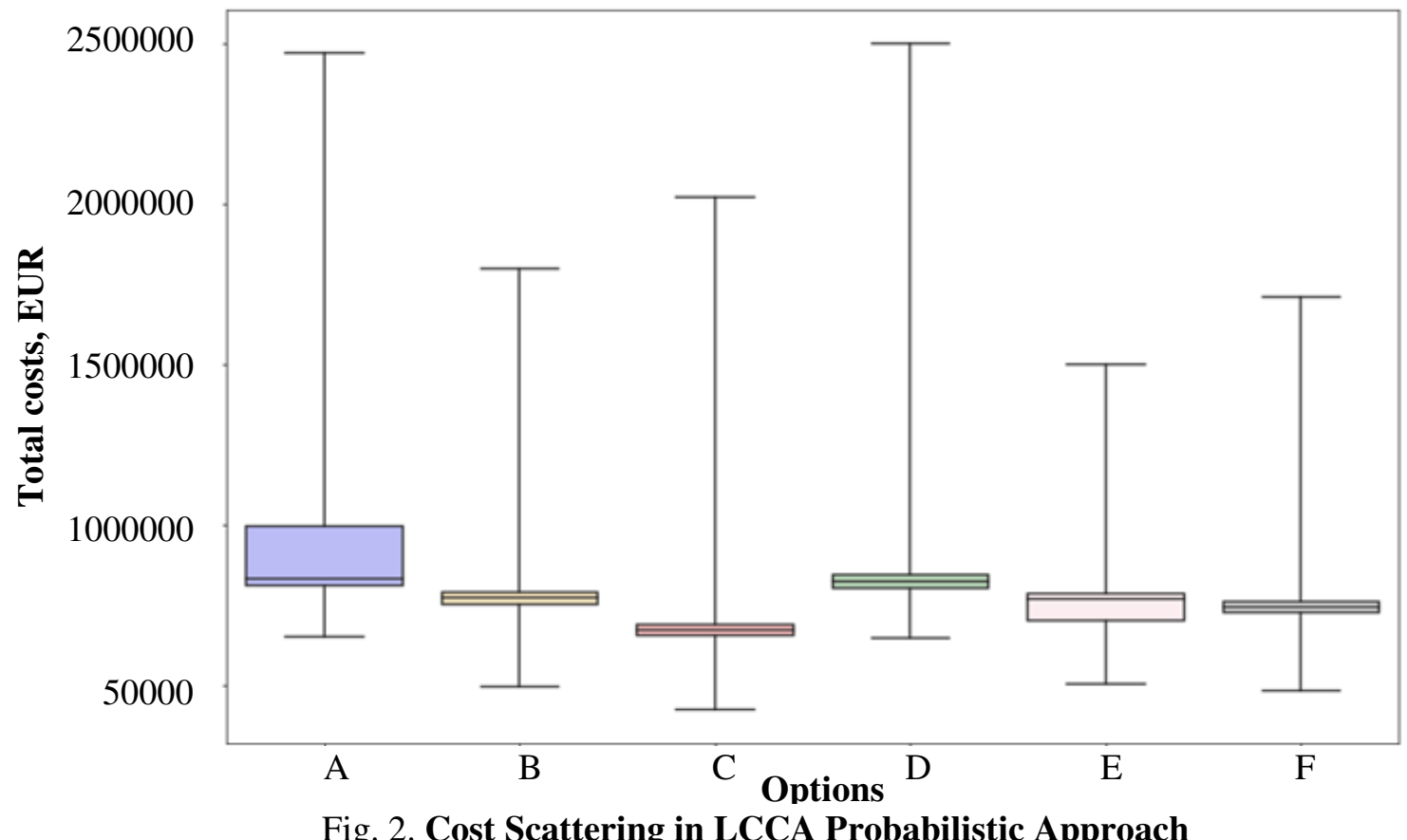




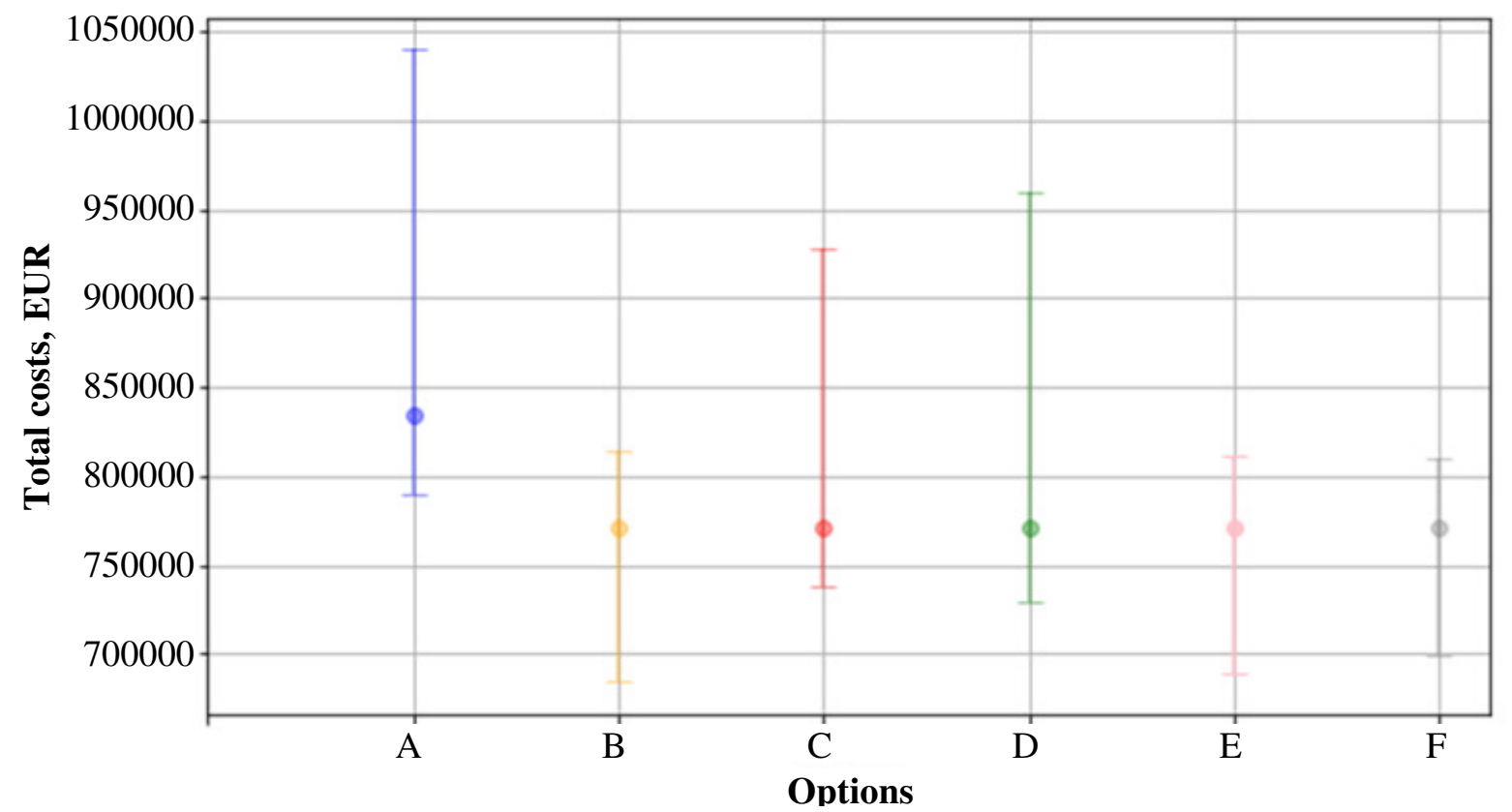

Fig. $3.95 \%$ confidence interval that costs will be within these limits

Figure 4 shows the relationship between the generated periods and costs. It reveals that, if the maintenance costs do not change on average (per year), then as the period increases, the total cost ratio to current prices decreases. Starting from 10 years, the cost decreases and is no longer as large as in previous years. The difference between the options does not differ significantly. It means that there is a functional relationship between the lifetime of the wearing course and the costs.

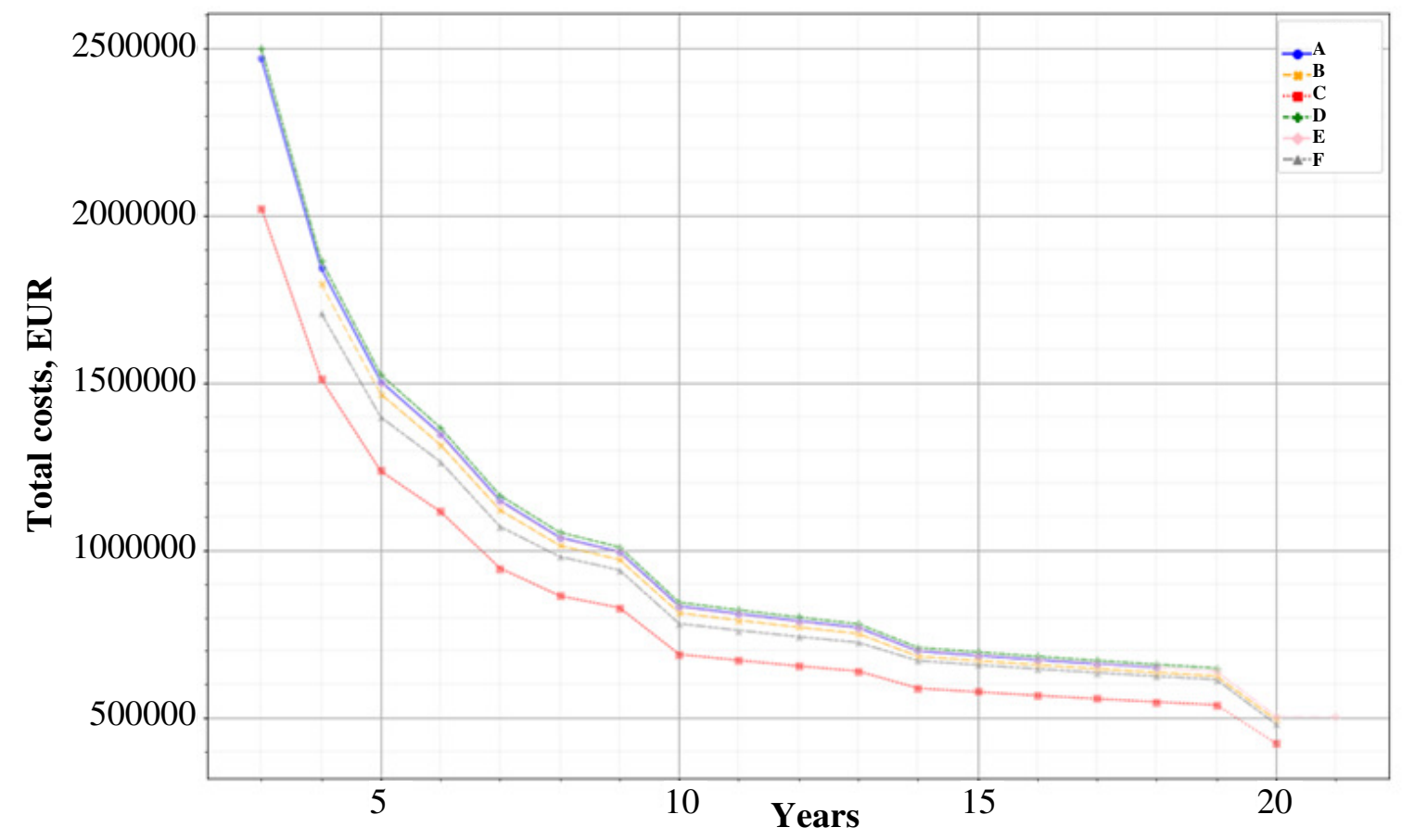

Fig. 4. Impact of lifetime of surface on road costs throughout its lifetime by option

\section{Results from testing BBTM}

In Latvia BBTM asphalt concrete type is not used. As the thin layer of asphalt concrete can save money in the long term, the design, testing, and specification of the asphalt concrete were carried out. Laboratory results are used as a basis to calculate LCCA. For the design of BBTM, aggregates of magmatic quartz diorite were selected. Polymer-modified bitumen (PMB) 45/80-55 was chosen as the binder for the mixture. Granulometric curves were designed according to EN 13108-2. The standard 
requirements are general, and the specifications of Hungary [17], Spain [18] and Poland [19] were studied. The binder content of the designed mixtures ranged from 5.2-5.6\%. The air voids were assumed to be between 3.0 and $6.9 \%$, as Latvia has a high percentage of studded tires on vehicles.

The designed mixes were tested on a wheel track test according to EN 12697-22 and the interlayer shear strength according to ALP A-StB, T.4. AC22 asphalt concrete with a thickness of $6 \mathrm{~cm}$ was chosen as the base course. Figure 5 shows BBTM11 ( the wearing course), which is compacted on the top of AC22 (the base course). In total, three different mixes were created (Mix 1, Mix 2, Mix 3). Three different emulsions (C50BP, C60BP, C65BP) were used between the layers. Manufactured mixtures showed high-quality results for the WTSAIR value (0.09 to 0.17) (see. Table 4). Interlayer shear results were 3-4 times higher than the Road Specification 2019 requirements (see Table 5) [20].

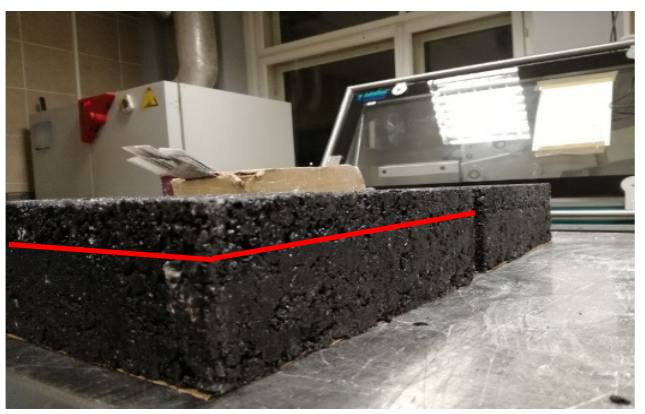

Fig. 5. BBTM 11 is compacted on top of AC22 base course

Table 4

Wheel track test results for BBTM mixtures

\begin{tabular}{|c|c|c|c|c|}
\hline $\begin{array}{c}\text { Type of } \\
\text { mixture }\end{array}$ & $\begin{array}{c}\text { Wheel tracking } \\
\text { slope, } \text { mm per } \\
\mathbf{1 0 0 0} \text { cycles }\end{array}$ & $\begin{array}{c}\text { Wheel tracking slope } \\
\text { (linear part), mm per } \\
\mathbf{1 0 0 0} \text { cycles }\end{array}$ & $\begin{array}{c}\text { Rut } \\
\text { depth, } \\
\text { mm }\end{array}$ & $\begin{array}{c}\text { Proportion rut } \\
\text { depth, \% }\end{array}$ \\
\hline Mix 1 & 0.11 & 0.15 & 3.8 & 4.5 \\
\hline Mix 2 & 0.09 & 0.13 & 3.6 & 4.3 \\
\hline Mix 3 & 0.17 & 0.20 & 4.3 & 5.1 \\
\hline
\end{tabular}

Table 5

Shear strength results between BBTM wearing course and AC22 base course

\begin{tabular}{|c|c|c|c|c|c|c|}
\hline $\begin{array}{c}\text { Type of } \\
\text { mixture }\end{array}$ & \multicolumn{2}{|c|}{ Mix 1 } & \multicolumn{2}{c|}{ Mix 2 } & \multicolumn{2}{c|}{ Mix 3 } \\
\hline \multirow{2}{*}{ Emulsion } & $\begin{array}{c}\text { Shear } \\
\text { strength, } \\
\text { kN }\end{array}$ & $\begin{array}{c}\text { Shear } \\
\text { distance, } \\
\text { mm }\end{array}$ & $\begin{array}{c}\text { Shear } \\
\text { strength, } \\
\text { kN }\end{array}$ & $\begin{array}{c}\text { Shear } \\
\text { distance, } \\
\text { mm }\end{array}$ & $\begin{array}{c}\text { Shear } \\
\text { strength, } \\
\text { kN }\end{array}$ & $\begin{array}{c}\text { Shear } \\
\text { distance, } \\
\text { mm }\end{array}$ \\
\hline \multirow{2}{*}{ C 50 BP } & 34.7 & 3.4 & 35.4 & 3.0 & 32.1 & 3.3 \\
\cline { 2 - 7 } & 45.1 & 4.2 & 36.0 & 4.1 & 33.9 & 4.3 \\
\hline \multirow{2}{*}{ C 60 BP } & 22.9 & 2.4 & 35.8 & 3.7 & 32.8 & 3.7 \\
\cline { 2 - 7 } & 28.6 & 2.8 & 36.0 & 3.8 & 36.5 & 4.4 \\
\hline \multirow{2}{*}{ C 65 BP } & 33.5 & 3.5 & 29.4 & 4.0 & 33.2 & 4.7 \\
\cline { 2 - 7 } & 31.0 & 2.8 & 30.9 & 3.3 & 35.1 & 4.4 \\
\hline
\end{tabular}

\section{Conclusions}

1. The main problems in creating LCCA calculations were to predict the service life of each asphalt concrete type. There are few roads within the road network of Latvia that have been preventively maintained. Therefore, the lack of data is the key to accurate LCCA analysis. Moreover, this makes it difficult to predict the service life of road pavement.

2. When performing LCCA with a probabilistic approach, the randomly generated period size could significantly affect the result, if the required number of reconstruction stages changes. 
3. The LCCA calculation for the deterministic and probabilistic approaches showed that the option C (BBTM11 + AC22) is the most sustainable over a 40-year period.

\section{Further work}

It is planned to develop the calendar reconstruction plan by comparing the materials. For comparison, tests, such as the wheel track test, fatigue test, interlayer shear strength test, thermal stress restrained specimen test will be used. It is also planned to perform LCCA analysis from the user side. LCA analysis will also be performed.

\section{Acknowledgement}

This study was co-financed by the European Regional Development (ERDF). Measure 1.1.1.1 "Industry-Driven Research" of specific objective 1.1.1 "To increase the research and innovation capacity of scientific institutions of Latvia and their ability to attract external funding by investing in human resources and infrastructure" within the project: No 1.1.1.1/16/A/148 "Innovative use of reclaimed asphalt pavement for sustainable road construction layers".

Many thanks to SJSC "Latvian State Roads" for supporting the research.

\section{References}

[1] Statistics from SJSC "Latvian State Roads". [online] [26.02.19] Available at: https://lvceli.lv/faq/\#cik-naudas-butu-nepieciesams-lai-savestu-kartiba-visus-valsts-autocelus

[2] Statistics from SJSC "Latvian State Roads". [online] [26.02.19] Available at: https://lvceli.lv/uncategorized/videja-satiksmes-intensitate-uz-valsts-galvenajiem-celiemturpinapieaugt/

[3] Walls III J., Smith M.R. Life-Cycle Cost Analysis in Pavement Design —Interim Technical Bulletin. September 1998.

[4] Danish Road Institute (DRI), Belgian Road Research Centre (BRRC), Swedish National Road and Transport Research Institute. OPTHINAL Optimization of Thin Asphalt Layers, 2011.

[5] EN 13108-2 standard "Bituminous mixtures. Material specifications. Asphalt Concrete for Very Thin Layers (BBTM)".

[6] University of California - Barkeley, Pavement Life-cycle Assessment Tool for Environmental and Economic Effects, 2013.

[7] Bonaquist R., Critical Factors Affecting Asphalt Concrete Durability, August, 2016.

[8] EAPA Beuving E., Use of SMA in Europe, February 2018.

[9] Aksnes J. Environmental Friendly Pavements Final report. Norwegian Public Roads Administration, 2009.

[10] Mineral Products Association, Association of Directors of Environment, Economy, Planning and Transport, Service life of asphalt materials for asset management purposes, June 2015.

[11] Nicholls C., Overview, including less common options, October 2009.

[12] Transport Roads\&Maritime Services, Qa Specification R121 stone mastic asphalt, July 2013

[13] Wilde W.J., Cost-Effective PavementPreservation Solutions for the Real World, September 2014

[14] Transportation Research Board of the National Academies, Preservation Approaches for HighTraffic-Volume Roadways, 2011.

[15] Durab Roads, Cost-effective durable roads by green optimized construction and maintenance, March 2015.

[16] Centrum voor Wiskunde en Informatica (1995). Python tutorial. Technical Report CS-R9526. Amsterdam: van Rossum, G.

[17] Asphalt concrete material requirements in Hungry, e-UT 05.02.11:2017, Hungary.

[18] Agencia Estatal Boletín Oficial del Estado. Bitumen mixes for asphalt concrete layers. Draining and discontinuous mixes, 2015, Spain.

[19] General Directorate for National Roads and Highways. Asphalt surfaces on national roads, 2014, Poland.

[20] SJSC “Latvian State Roads”, Road Specification 2019, Riga, 2019. 